\title{
PEMANTAUN PARAMETER DINAMIKA POPULASI IKAN KEMBUNG (Rastrelliger sp) DI PERAIRAN PESISIR PULAU TERNATE PROVINSI MALUKU UTARA
}

\author{
Umar Tangke \\ Staf Pengajar Faperta UMMU-Ternate, e-mail: khakafart@yahoo.com
}

\begin{abstract}
ABSTRAK
Penelitian dengan tujuan untuk memantau tingkat eksploitasi sumberdaya dengan mengkaji aspek dinamika populasi ikan kembung (Rastrelliger sp) di perairan peisisir pulau Ternate di laksanakan selama pada bulan Juli sampai September 2014 dengan pengumpulan sampel dari hasil tangkapan nelayan dengan menggunakan alat tangkap gill net dan mini purse seine. Data hasil pengkuran di analisis dengan menggunakan program Microsoft excel 2010 dan program FISAT untuk mengestimasi aspek dinamika populasi ikan. Hasil yang didapat adalah nilai $L_{\infty}=28.46$, nilai $K=0.710 /$ tahun, nilai $t_{0}=-0.24$, nilai $M=1.47$, nilai $F=1.72$, nilai $\mathrm{Z}=3.19$. hasil ini menunjukan bahwa ikan kembung yang tertangkap oleh nelayan memiliki laju pertumbuhan yang cepat serta tingkat kematian yang tinggi, sehingga umumnya ikan kembung yang tertangkap adalah ikan yang belum melakukan pemijahan. Hasil analisis $Y / R$ dan $B / R$ menunjukan bahwa tingkat eksploitasinya cukup tinggi dengan nilai $E=0.54$.
\end{abstract}

Kata Kunci: Rastrelliger sp, ikan kembung, pesisir pulau Ternate

\section{PENDAHULUAN}

\subsection{Latar Belakang}

Pemanfaatan sumberdaya perikanan di Provinsi Maluku Utara lebih didominasi oleh perikanan tangkap $82.46 \%$ dengan jumlah potensi sumberdaya ikan yang dapat dimanfaatkan diperkirakan mencapai 150.997 ton/tahun untuk jenis ikan pelagis dan ikan demersal (DKP. Prov. Malut, 2010). Perairan pulau Ternate merupakan bagian dari provinsi Maluku Utara dan merupakan salah satu perairan yang sangat berperan dalam menyumbang produksi perikanan tangkap khususnya jenis ikan pelagis dan ikan demersal. Potensi perikanan tangkap perairan pulau Ternate diperkirakan sebesar $47.838,25$ ton/tahun dan baru dimanfaatkan sebesar 23.919,25 ton/tahun. Perairan pulau Ternate terletak di pesisir Barat Pulau Halmahera dengan aktifitas nelayan yang didominasi oleh perikanan rakyat dengan daerah penangkapan berada pada wilayah 1 - 3 mil atau di pesisir perairan pulau Ternate (Gambar 1).
Jenis hasil tangkapan ikan lebih didominasi oleh ikan pelagis kecil diantaranya ikan layang (Decapterus spp), ikan komo (Auxis thazard), ikan kembung (Rastrelliger sp), ikan selar (Selaroides sp) dan jenis ikan pelagis kecil lainnya (DKP Kota Ternate, 2011). Ikan kembung (Rastrelliger sp) (Gambar 2) merupakan salah satu komoditi perikanan tangkap kota Ternate dengan total produksi rata-rata adalah lebih $438 \mathrm{~kg} / \mathrm{bulan}$ yang di tangkap menggunakan alat tangkap jaring lingkar (mini purse seine) dan jaring insang (Gill net) dengan waktu operasi penangkapan rata-rata adalah 1-2 kali operasi penangkapan per hari.

Melihat jenis alat tangkap yang digunakan serta intensifnya jumlah waktu operasi penangkapan sumberdaya ikan kembung di perairan pesisir pulau Ternate, maka kelestarian sumberdaya ikan kembung tersebut perlu di kajiagar dapat dimanfaatkan secara terus menerus. Agar dapat menjaga kelestariannya, maka pemanfaatan dan pengelolaannya harus dilaksanakan secara 
rasional. Informasi mengenai dinamika populasi ikan kembung (Rastrelliger sp) dari daerah yang bersangkutan diharapkan dapat dipergunakan sebagai dasar pengelolaannya. Pengkajian parameter dinamika populasi ikan meliputi panjang asimtot $(\mathrm{L} \infty)$, koefisien pertumbuhan (K), kematian total (Z), kematian alami (M), kematian karena penangkapan (F), laju eksploitasi (E), ukuran pertamakali tertangkap oleh alat tangkap (Lc), yield per rekrut relatif $\left(\mathrm{Y} / \mathrm{R}^{\prime}\right)$, biomassa per rekrut relatif $\left(B / R^{\prime}\right)$. Informasi tersebut sangat penting diketahui sebagai informasi untuk pemanfaatannya sehingga sumberdaya ikan kembung di perairan pesisir pulau Ternate dapat terjaga dan memberikan manfaat bagi masyarakat nelayan.

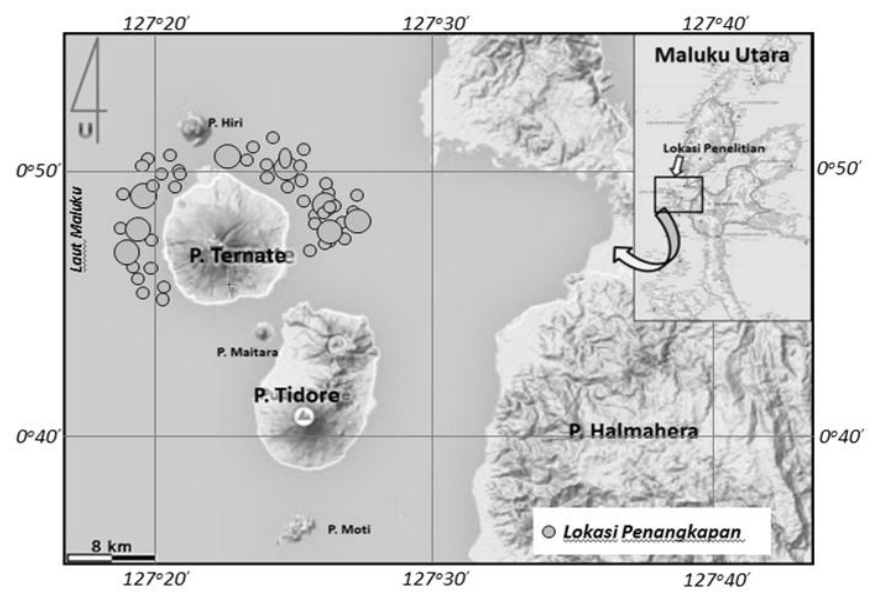

Gambar 1. Peta Perairan Ternate dan Lokasi Tangkapan Ikan Kembung (Rastrelliger sp)

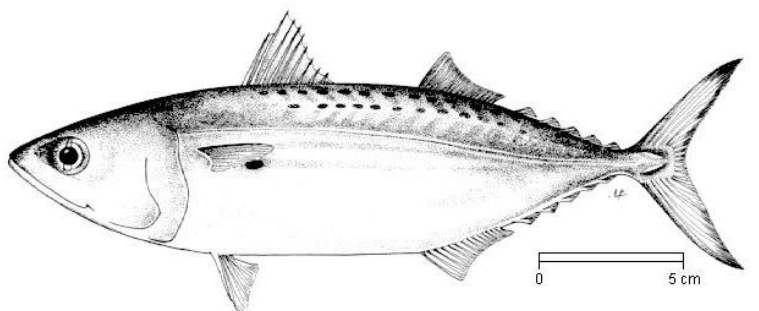

Gambar 2. Ikan Kembung (Rastrelliger sp)

\subsection{Tujuan dan manfaat Penelitian}

Peneltian ini bertujuan untuk memantau tingkat eksploitasi sumberdaya ikan kembung dengan mengkaji aspek dinamika populasi di perairan pesisir pulau Ternate sehingga dapat menjadi bahan infomasi kepada pengguna dan DKP Kota Ternate dalam pengelolaan sumberdaya ikan kembung di tersebut.

\section{METODE PENELITIAN}

Sampel ikan kembung (Rastrelliger sp) di kumpulkan dari hasil tangkapan nelayan selama bulan Juli sampai Bulan September 2014 di perairan pesisir pulau Ternate dan sekitarnya. Pengukuran sampel dilakukan di Laboratorium Pengolahan Hasil Perikanan Universitas Muhammadiyah Maluku Utara.
Data hasil pengukuran kemudian ditabulasi kedalam tabel distribusi frekuensi dengan selang $0.6 \mathrm{~cm}$ menggunakan program Excel 2010, data selanjutnya dianalisis menggunakan Program FISAT dengan sub program Elefan I untuk mengestimasi panjang infinity $(\mathrm{L} \infty)$ dan koefisien pertumbuhan $(\mathrm{K})$, sesuaiformula yang dikemukakan oleh Von Bertalanffy (Sparre et.al, 1999) dengan persamaan matematisnya adalah :

$$
\mathrm{L}_{\mathrm{t}}=\mathrm{L} \infty\left(1-\exp ^{-K\left(t-t_{0}\right)}\right)
$$

Keterangan:

$\mathrm{L}_{\mathrm{t}}=$ Panjang ikan kembung $(\mathrm{cm})$ pada umur $\mathrm{t}$ (tahun)

L $\infty$ Panjang asimptot ikan kembung $(\mathrm{cm})$

$\mathrm{K}=$ Koefisien pertumbuhan (per tahun) 
$t_{0}=$ Umur teoritis ikan kembung pada saat panjangnya sama dengan nol (tahun)

$\mathbf{t}=$ Umur ikan kembung (tahun)

Pendugaan umur teoritis pada saat panjang ikan kembung sama dengan nol ( $\left.t_{0}\right)$ sesuai rumus empiris Pauly dalam Sparre et al. (1999) yaitu :

$\log \left(-t_{0}\right)=-0,3922-0,2752 \log L_{\infty}-1,308 \log K$

to adalah Umur teoritis ikan kembung pada saat panjangnya sama dengan nol (tahun). Mortalitas total (Z) diduga menggunakan metode kurva yang dikonversi ke panjang. Metode kurva ini telah tergabung dalam program FISAT-II (Gayanilo Jr et al., 1996). Laju mortalitas alami (M) diduga dengan menggunakan hubungan empiris (Pauly,1980):

$\log M=0.0066-0.279 \log L \infty+0.6543 \log K+0.4634$

LogT .

L $\infty=$ parameter pertumbuhan $(\mathrm{cm})$ dan $T$ = rata-rata suhu lingkungan perairan tahunan $\left({ }^{\circ} \mathrm{C}\right)=29.4^{\circ} \mathrm{C}$. Mortalitas penangkapan $(\mathrm{F})$ ditentukan dengan mengurangkan $M$ terhadap $\mathrm{Z}$ dan laju eksploitasi (E) ditentukan dari Z/F serta ukuran pertama kali tertangkap (Lc) dihitung dengan bantuan paket program FISAT-II (Gayanilo Jr et al., 1996). Yield Per Recruitment dan biomassa per rekrut relatif $\left(B / R^{\prime}\right.$,) sebagai fungsi dari $E$ ditentukan dari dugaan parameter pertumbuhan dan probabilitas hasil tangkapan (Pauly and Soriano 1986) dengan menggunakan alat bantu program FISAT-II

\section{HASIL DAN PEMBAHASAN}

\subsection{Kelompok Umur}

Sampel ikan kembung yang dipakai selama penelitian merupakan hasil tangkapan dari nelayan yang menggunakan alat tangkap gill net dan mini purse seine selama bulan Juli sampai September 2014 dengan lokasi penangkapan berada pada jarak 1 - 3 mil dari pesisir pulau Ternate. Jumlah sampel yang dipakai untuk analisis adalah 1.189 ekor dengan ukuran panjang terkecil $13.4 \mathrm{~cm}$ dan ukuran panjang terbesar adalah $27.4 \mathrm{~cm}$. sampel ikan selanjutnaya dibagi dalam 3 kelompok umur dengan jumlah kelas sebanyak 24 kelas pada interval $0.6 \mathrm{~cm}$.
Kelompok umur diduga melalui analisis sebaran frekuensi panjang karena frekuensi panjang ikan umumnya berasal dari umur yang sama dan cenderung akan membentuk sebaran normal. Berdasarkan metode normal separation yang terdapat pada paket program Fisat II dapat menggambarkan jumlah kohort dari sebaran frekuensi panjang. Grafik pertumbuhan ikan kembung pada Gambar 3, menunjukan bahwa ikan kembung yang tertangkap setiap pengambilan sampel di perairan peisisir pulau Ternate terdapat satu modus panjang, terlihat pula terjadi pergeseran modus tiap pengambilan sampel ikan yang juga memnggambarkan terjadinya penambahan ukuran panjang ikan kembung setiap bulan mulai dari pengambilan sampel pertama pada bulan Juli hingga September 2014. Pada Gambar 3 terlihat terjadi pertumbuhan panjang masing-masing kohort dengan selang waktu masing-masing pertumbuhan selam satu bulan.

\subsection{Pertumbuhan}

Pendugaan panjang infiniti $(\mathrm{L} \infty)$ dan koefisien pertumbuhan (K) ikan kembung di perairan pesisir pulau Ternate dengan menggunakan formula pertumbuhan von Bertalanfy masing-masing adalah $\mathrm{L}^{\infty}=28.46$ $\mathrm{cm}, \mathrm{K}=0.710$ per tahun dan $\mathrm{t}_{0}=-0.24$. Nilai dugaan parameter pertumbuhan di estimasi dengan menggunakan program FISAT sub program ELEFAN I dengan routin Response Surface $\mathbf{R} \mathbf{n}=0.96$. Berdasarkan parameter pertumbuhaan $\mathrm{L}_{\infty}, \mathrm{K}$ dan $\mathrm{t}_{0}$, maka kurva pertumbuhan ikan kembung di perairan peisir pulau Ternate seperti terlihat pada Gambar 4 dengan persamaan pertumbuhannya adalah Lt $=28.46\left[1-\exp ^{-0.710(t+0,24)}\right]$. Dugaan persamaan pertumbuhan jika dibuat hubungan umur terhadap panjang tubuh ikan kembung, maka terlihat bahwa populasi ikan kembung yang tertangkap di pesisir pulau Ternate berumur sekitar 0.8 - 4.6 tahun.

Nilai dugaan parameter pertumbuhan $\mathrm{L} \infty=28.46$ dan $\mathrm{K}=\mathbf{0 . 7 1 0}$ pertahun di perairan pesisir pulu Ternate tersebut jika dibandingkan dengan nilai $\mathrm{L}^{\infty}$ dan nilai $\mathrm{K}$ yang didapat oleh peneliti lainnya pada spesies yang sama di perairan yang berbeda diantaranya Mose dan Hutubessy (1996), L $\infty=33 \mathrm{~cm}, \mathrm{~K}=1.37$, Nurhakim (1993), $\mathrm{L}^{\infty}=26.33 \mathrm{~cm}, \mathrm{~K}=0.759$ dan 
Suhendra dan Amin (1990),

$\mathrm{L} \infty=24.70, \mathrm{~K}$

Ternate mempunyai pertumbuhan yang lebih = 1.15, dan Suwarso (2010) $\mathrm{L}_{\infty}$ 21.6. Nilai $\mathrm{L}_{\infty}$ dan $K$ ikan kembung yang diperoleh di perairan pesisir pulau Ternate lebih besar dari nilai $L \infty$ dan $K$ hasil penelitian Nurhakim di Laut Jawa serta Suhendra dan Amin di Selat Malaka serta Suwarso di Teluk Jakarta hal ini menjelaskan ikan kembung di perairan pulau baik dibandingkan dengan ikan kembung yang tertangkap di perairan Laut Jawa, Selat Malaka dan Teluk Jakarta. Tingginya nilai parameter pertumbuhan ikan kembung di perairan pulau Ternate dan perairan pulau Ambon diduga ada hubungannya dengan faktor kondisi ekobiologi dari habitat kedua perairan tersebut.

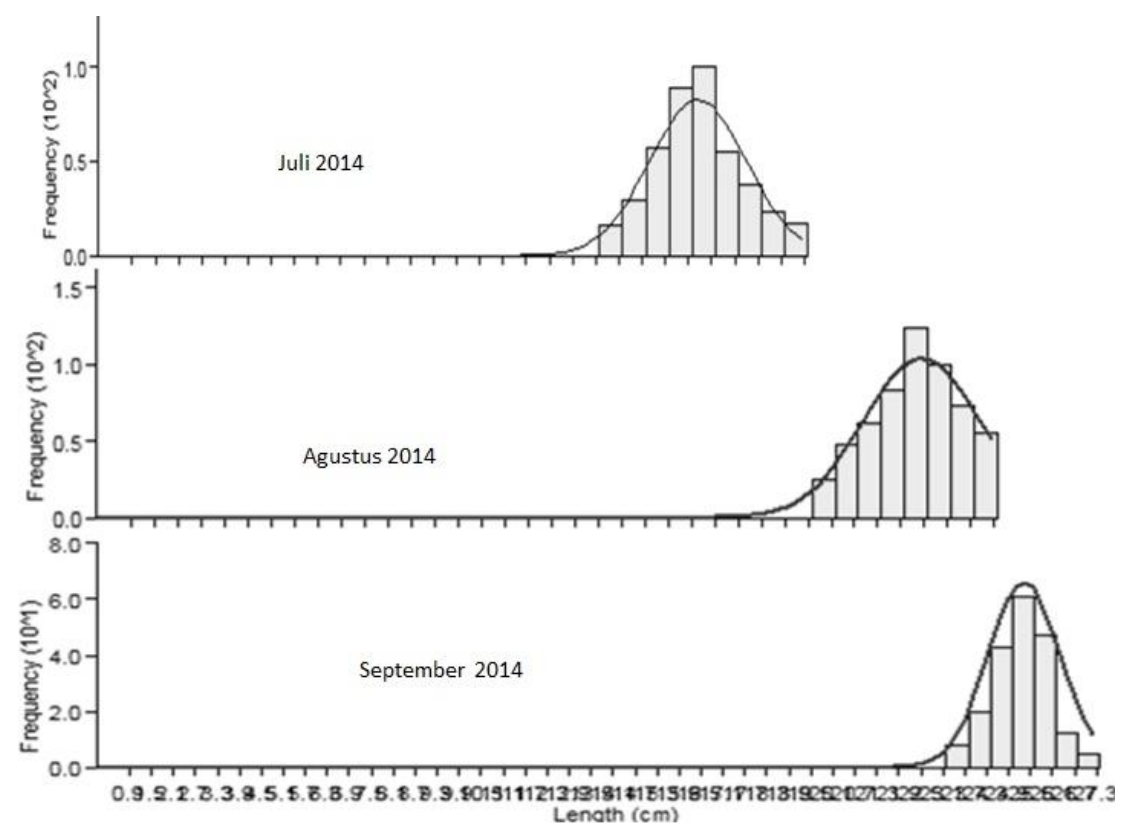

Gambar 3. Sebaran Kelompok Umur Ikan Kembung di Pesisir Pulau Ternate

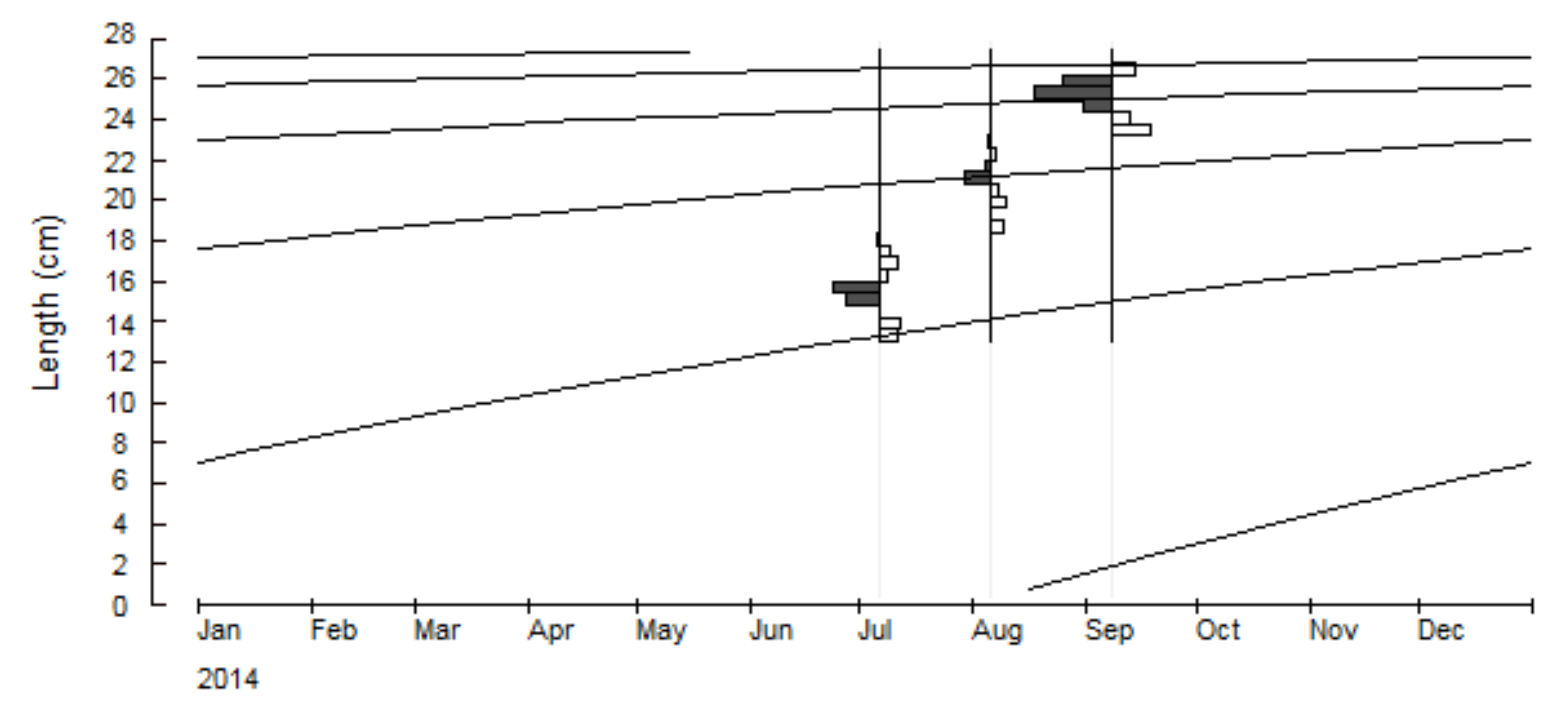

Gambar 4. Kurva Pertumbuhan Ikan Kembung (Rastrelliger sp) di Pesisir Pulau Ternate

Jika nilai $L \infty$ dan $K$ diperairan pulau Ternate dibandingkan dengan hasil penelitian Mose dan Hutubessy (1996) di perairan Ambon, maka nilai $\mathrm{L} \infty$ dan $\mathrm{K}$ diperairan pulau Ternate lebih kecil. Kecilnya nilai $\mathrm{L} \infty$ dan $\mathrm{K}$ ini diduga akibat tingkat eksploitasi terlalu tinggi hal ini dibuktikan dengan jumlah operasi penangkapan yang dilakukan oleh nelayan pulau Ternate dengan jumlah operasi penangkapan 1-2 kali operasi per hari. Tingginya tingkat eksploitasi ini menyebabkan terjadinya degradasi morfometrik terhadap sumberdaya ikan kembung yang ada di perairan pulau Ternate selain itu hasil 
penelitian Suruwaky dan Gunaisah (2013) di perairan Sorong dan sekitarnya juga menemukan degradasi morfometrik ikan kembung akibat tingkat eksploitasi yang tinggi diakibatkan oleh laju penangkapan yang terlalu tinggi.

\subsection{Mortalitas dan Laju Eksploitasi}

Moratalitas tahunan M. F, dan Z ikan kembung diperoleh masing-masing 1.47; 1.72; dan 3.19 pertahun. Kurva hasil tangkapan dalam menduga nilai $Z$ (Gambar 5). Perhitungan nilai $Z$ yang didasari nilai
$R^{2}$ terbesar pada analisis regresi. Nilai $r$ untuk persamaan regresi adalah 0,89. Nilai dugaan kematian karena penangkapan (F) sebesar $\mathbf{1 . 7 2}$ pertahun diperoleh dari pengurangan nilai $M$ terhadap Z. pada Gambar 5 kurva hasil tangkapan untuk menduga nilai $Z$, dapat dilihat bahwa Lingkaran hitam digunakan untuk perhitungan nilai $\mathrm{Z}$ yang didasari nilai $\mathbf{R}^{2}$ terbesar pada analisis regresi dengan lingkaran kosong merupakan data yang belum rekrut. Nilai $r$ untuk regresi adalah $0.89, a=$ 13.30 dan $b=0.46$.

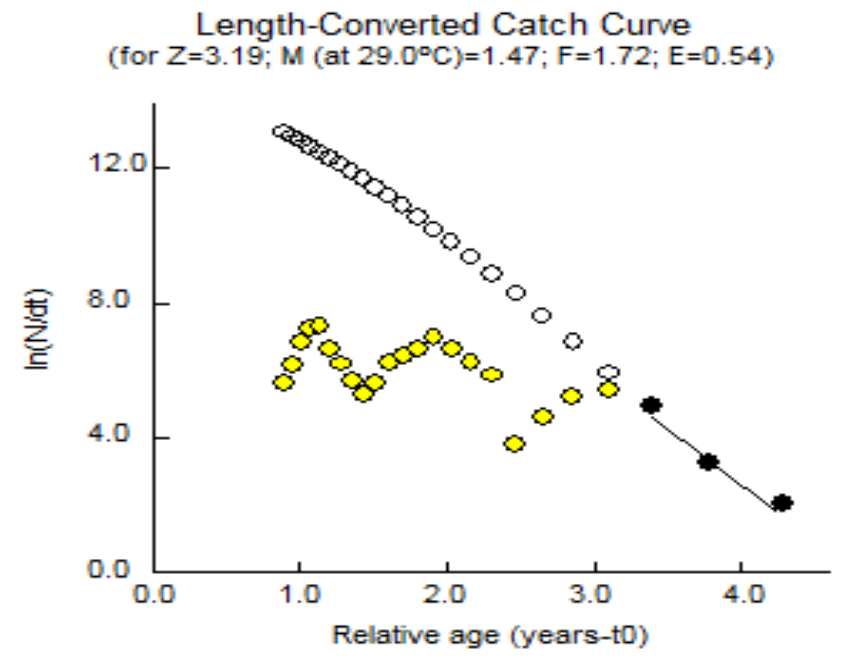

Gambar 5. Kurva Hasil Tangkapan Ikan Kembung Di Perairan Pulau Ternate 2014.

Nilai dugaan Mortalitalis total (Z) dari penelitian ini sebesar 3.19 pertahun terlihat lebih kecil dari nilai dugaan $\mathrm{Z}$ yang diperoleh Oktaviani (2013), yaitu 7.37 pertahun. Hal ini akibat dari kematian karena penangkapan yang tinggi dari ikan kembung ( $F$ = 1.72 pertahun) yang diperoleh dari penelitian ini. Kematian alami (M) yang diduga dengan menggunakan formula empiris Pauly pada penelitian ini sebesar 1.47 lebih kecil bila dibandingkan dengan hasil penelitian lainnya pada spesies yang sama, yaitu 5.91 pertahun (Oktaviani, 2013). Nilai dugaan laju Eksploitasi (E) untuk ikan kembung pada daerah penelitian sebesar 0.54 ( $\mathrm{E}>0.50)$. Menurut Gulland (1971) bahwa suatu sumberdaya yang dieksploitasi dalam kondisi optimun apabila nilai $F=M$, yaitu Eopt $=0,5$. Jadi pemanfaatan ikan Kembung di perairan pesisir Pulau Ternate telah melebihi batas maksimum (Sparre et al., 1989).

\subsection{Selektifitas Penangkapan}

Dimensi ikan berpengaruh terhadap peluang ikan untuk lolos dan atau tertahan pada jaring. Hubungan antara peluang tertangkapnya ikan oleh jaring dengan dimensi atau panjang tubuh ikan dapat diplot ke dalam bentuk grafik, sehingga akan diperoleh satu pola yang disebut kurva seleksi penangkapan. Kurva ini kemudian digunakan untuk menduga panjang ikan mula-mula yang tertangkap oleh jaring (Lc). Untuk jaring tidak selektif peluang untuk Lc ini dianggap $50 \%$. Dengan menggunakan program FISAT-II, diperoleh dugaan Lc ikan kembung di perairan pesisir pulau Ternate $14.90 \mathrm{~cm}$. Berdasarkan persamaan pertumbuhan von Bertalanffy yang diperoleh, umur ikan kembung pada saat pertama kali tertangkap (Lc) adalah 8 bulan dengan panjang $14.90 \mathrm{~cm}$. Nilai dugaan Lc di 
inimenunjukkan bahwa rata-rata ukuran ikan yang tertangkap oleh alat yang beroperasi merupakan kelompok ikan yang masih muda dan belum sempat melakukan pemijahan tahunan. Untuk menjaga ketersediaan dan kelestarian stok spesies ikan kembung di perairanpesisir pulau Ternate, maka diupayakan nilai Lc tersebut ditingkatkan agar ikan kembung yang tertangkap minimal telah melakukan pemijahan dengan ukuran panjang > $24 \mathrm{~cm}$ (Mosse dan Hutubessy, 1996), > $20.71 \mathrm{~cm}$ (Oktaviani, 2013).
3.5. Hasil per Rekrutmen Relatif.

Fungsi $\mathrm{Lc} / \mathrm{L} \infty$ dan $\mathrm{M} / \mathrm{K}$ sangat menentukan nilai $Y / R$ dan $B / R$, dimana nilai masing-masing $\mathrm{Lc} / \mathrm{L} \infty$ dan $\mathrm{M} / \mathrm{K}$ adalah 0.051 dan 2.12. Dengan nilaiLc sebesar $14.90 \mathrm{~cm}$ nilai $E_{\text {maks }}=0.364$ pertahun menghasilkan $\mathrm{Y} / \mathrm{R}$ maksimum sebesar0.016 dan biomassa per recruit pada Emaks sebesar 0.259 atau $25.9 \%$ dari bimassa virgin. Laju eksploitasi saat ini(Gambar 6) adalahE $=0.54$ dimana nilai ini menunjukan bahwa laju eksploitasi telah lebih tangkap dengan nilai dugaan pemanfaatan sebesar $56.4 \%$.

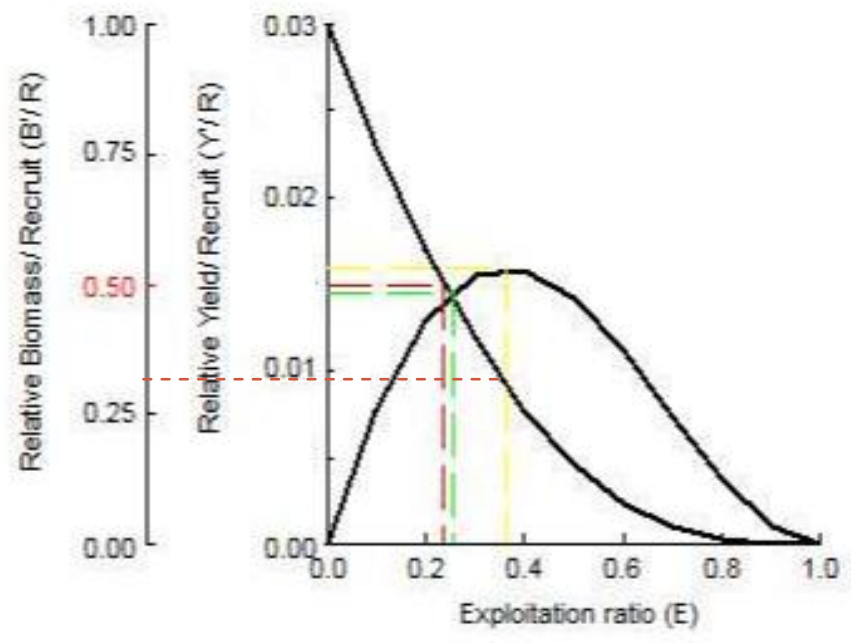

Gambar 6. Grafik Hasil Tangkapan Per Rekrutmen Relatif Ikan Kembung di Pesisir Pulau Ternate

\section{PENUTUP}

Hasil analisis dinamika populasi ikan kembung di perairan pesisir pulau Ternate dapat disimpulkan bahwa ikan kembung yang tertangkap di perairan pesisir Pulau Ternate memiliki laju pertumbuhan cepat serta tingkat kematian yang tinggi, dimana umumnya yang tertangkap oleh nelayan adalah ikan kembung dengan ukuran 14.90 yakni ukuran ikan yang belum melakukan pemijahan selain dapat dilihat juga bahwa laju eksploitasi ikan kembung pada perairan pesisir pulau Ternate telah lebih tangkapan dengan nilai $\mathrm{E}=0.54$.

\section{DAFTAR PUSTAKA}

DKP Provinsi Maluku Utara. 2010. Laporan Tahunan Produksi Perikanan Tangkap.

DKP Kota Ternate. 2011. Statistik Perikanan Tangkap Kota Ternate.

Gulland, J.A. 1971. Fish Resources of the Ocean. Fishing New Books, London, 255p.

Nurhakim S., 1993. Beberapa Parameter Populasi Ikan Banyar (Rastrelliger kanagurta) di Perairan Laut Jawa. Jurnal Penelitian Perikanan Laut. Hal 64-75.

Oktaviani, D. 2013. Etnozoologi, Biologi Reproduksi, Dan Pelestarian Ikan Lema Rastrelliger Kanagurta (Cuvier, 1816) Di Teluk Mayalibit Kabupaten Raja Ampat Papua Barat Indonesia. Disertasi Fakultas MIPA Program Pascasarjana Universitas Indonesia.

Saputra, S. W., 2007. Dinamika Populasi. Bahan Ajar Mata Kuliah Dinamika Populasi. Program Studi Manajemen Sumberdaya Perairan. FPIK. Universitas Dipenogoro. Semarang 
Suhendrata, T dan E. M. Amin. Pendugaan Pertumbuhan dan Pola Penambahan Baru IKan Kembung Lelaki ( $R$ kanagurta) di Perairan Selat Madura. Jurnal Penelitian Perikanan Laut No. 54, Hal 59-64.

Sparre P. dan S. C. Venema. 1999. Introduksi Pengkajian Stok Ikan Tropis Buku I Manual (Edisi Terjemahan). Kerjasama Organisasi Pangan, Perserikatan Bangsa-bangsa dengan Pusat Penelitian dan Pengembangan Perikanan, Badan Penelitian dan Pengembangan Pertanian, Jakarta.

Suruwaky A. M. dan Gunaisah E., 2013 Identifikasi Tingkat Eksploitasi Sumberdaya Ikan Kembung Lelaki (Rastrelliger kanagurta) Di tinjau dari Hubungan Panjang Berat. Jurnal Akuatika Vol. IV No. 2. ISSN 0853-2523. Hal. 131-140.

Suwarno, 2010. Biologi Reproduktif, Preferensi Habitat Pemijahan Dan Dugaan Stok Pemijah Ikan Kembung (Rastrelliger brachysoma) di Pantai Utara Jawa. Laporan Program Intensif Peningkatan Kemampuan Peneliti dan Rekayasa. Balai Riset Perikanan Laut. BRPKP, Kementrian Kelautan dan Perikanan. 